\title{
Expression profiling of 11ß-hydroxysteroid dehydrogenase type-1 and glucocorticoid-target genes in subcutaneous and omental human preadipocytes
}

\author{
I J Bujalska1, M Quinkler ${ }^{1,3}$, J W Tomlinson ${ }^{1}$, C T Montague ${ }^{2}$, D M Smith ${ }^{2}$ and P M Stewart ${ }^{1}$ \\ ${ }^{1}$ Division of Medical Sciences, The Medical School, Institute of Biomedical Research, University of Birmingham, Edgbaston, Birmingham B15 2TT, UK \\ ${ }^{2}$ Diabetes Drug Discovery, AstraZeneca, Alderley Park, Macclesfield, Cheshire SK10 4TG, UK \\ ${ }^{3}$ Clinical Endocrinology, Campus Mitte, Charité Universitätsmedizin Berlin, Berlin, Germany
}

(Requests for offprints should be addressed to P M Stewart; Email: p.m.stewart@ bham.ac.uk)

\begin{abstract}
Obesity is associated with increased morbidity and mortality from cardiovascular disease, diabetes and cancer. Although obesity is a multi-factorial heterogeneous condition, fat accumulation in visceral depots is most highly associated with these risks. Pathological glucocorticoid excess (i.e. in Cushing's syndrome) is a recognised, reversible cause of visceral fat accumulation. The aim of this study was to identify depot-specific glucocorticoid-target genes in adipocyte precursor cells (preadipocytes) using Affymetrix microarray technique. Confluent preadipocytes from subcutaneous (SC) and omental (OM) adipose tissue collected from five female patients were treated for $24 \mathrm{~h}$ with $100 \mathrm{nM}$ cortisol (F), RNA was pooled and hybridised to the Affymetrix U133 microarray set. We identified 72 upregulated and 30 downregulated genes by F in SC cells. In OM preadipocytes, 56 genes were increased and 19 were decreased. Among the most interesting were transcription factors, markers of adipocyte differentiation and glucose metabolism, cell adhesion and growth arrest protein factors involved in G-coupled and Wnt signalling. The Affymetrix data have been confirmed by quantitative realtime PCR for ten specific genes, including HSD11B1, GR, C/EBP $\alpha, C / E B P \beta, I L-6, F A B P 4, A P O D$, IRS2, AGTR1 and GHR. One of the most upregulated genes in OM but not in SC cells was HSD11B1. The GR was similarly expressed and not regulated by glucocorticoids in SC and OM human preadipocytes. C/EBP $\alpha$ was expressed in SC preadipocytes and upregulated by $F$, but was below the detection level in OM cells. C/EBP $\beta$ was highly expressed both in SC and in OM preadipocytes, but was not regulated by $\mathrm{F}$. Our results provide insight into the genes involved in the regulation of adipocyte differentiation by cortisol, highlighting the depot specifically in human adipose tissue.
\end{abstract}

Journal of Molecular Endocrinology (2006) 37, 327-340

\section{Introduction}

The magnitude and severity of the obesity epidemic (Kopelman 2000) have provided the impetus to further understand its genetic basis as well as focussing attention on the neuroendocrine regulation of appetite control and energy expenditure and adipocyte cell biology. Crucially, fat distribution is of pivotal importance with central or visceral adiposity conferring the greatest risk of premature mortality (Jensen 1997), and therefore, there is a need to define factors that regulate adipose distribution. Human adipose tissue exhibits different properties depending on their anatomical localisation, and has different sensitivity to glucocorticoids (Bujalska et al. 1997, Fried et al. 1998).

Clinical observations in patients with Cushing's syndrome who develop reversibly central obesity highlight the importance of glucocorticoids in this regard (Rebuffe-Scrive 1988). Glucocorticoids (GCs) induce adipocyte differentiation (Hauner et al. 1987) preferentially within visceral adipose tissue due to increased glucocorticoid receptor (GR) expression (Bronnegard et al. 1990), although other tissue-specific factors may be important.

In human adipose tissue, cortisol availability to bind and activate GR is controlled by $11 \beta$-hydroxysteroid

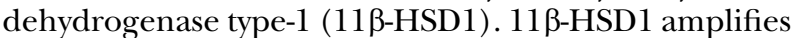
glucocorticoid action by reducing inactive cortisone (E) to active cortisol (F) (Lakshmi \& Monder 1988) and is highly expressed in omental (OM) compared with subcutaneous (SC) fat. Furthermore in primary adipose cultures, 11ß-HSD1 expression and activity are induced by F itself (Bujalska et al. 1997), thus representing a novel mechanism whereby cells can generate $F$ locally independent of circulating concentrations. Several factors are known to regulate 11ß-HSD1 expression and activity in the liver (Jamieson et al. 1995) and adipocytes; the most potent inducers are glucocorticoids, cytokines (leptin, tumour necrosis factor (TNF) $\alpha$, interleukin (IL)-1 $\beta$, IL-4, IL-6 and IL-14; Handoko et al. 2000, Tomlinson et al. 2001) and peroxisome proliferator activated receptor (PPAR $\gamma$ ) agonists (Berger et al.

DOI: $10.1677 / \mathrm{jme} .1 .02048$ Online version via http://www.endocrinology-journals.org 
2001, Laplante et al. 2003). Additionally, a significant role for $\mathrm{C} / \mathrm{EBP}$ transcription factors in regulating rat hepatic 11 $\beta$-HSD1 has been reported (Williams et al. 2000). Amongst the factors suppressing 11 $\beta$-HSD1 activity are: growth hormone, insulin-like growth factor-I (IGF-I) (Moore et al. 1999, Tomlinson et al. 2001), liver X receptors (Stulnig et al. 2002), PPAR $\alpha$ agonists (Hermanowski-Vosatka et al. 2000) and pituitary hormones like corticotrophin-releasing hormone and adrenocorticotrophin hormone (Friedberg et al. 2003).

Microarray approaches have been increasingly used to study gene profiling during adipocyte differentiation; however, most of these studies were carried out on mouse cell lines and not on human primary preadipocyte cultures (Burton et al. 2002, Jessen \& Stevens 2002, Wang et al. 2004). On this background, we aimed to identify factors that might regulate $11 \beta$-HSD1 gene transcription in human OM versus SC adipose tissue. We have also hypothesised that the identification of GR-induced target genes in human OM versus SC adipose tissue will increase our knowledge base of the predilection of glucocorticoids to increase visceral fat mass and might reveal exciting candidate targets involved in the pathogenesis of central obesity.

\section{Materials and methods}

\section{Human preadipocyte cell culture}

Paired SC and OM abdominal adipose tissue was obtained from five females (mean age $44 \cdot 8$ years, mean body mass index $29 \cdot 4 \mathrm{~kg} / \mathrm{m}^{2}$; patient details shown in Table 1). All patients were undergoing hysterectomy and not on any hormonal treatment. Tissues were dispersed with collagenase 1 as described earlier (Bujalska et al. 1999). Preadipocytes were seeded in Dulbecco's Modified Eagle's Medium/Ham's Nutrient Mixture F-12 (DMEM/F12) media with 10\% FCS into six-well tissue culture dish and cultured to confluence for 4-6 days. Media were changed every other day. The study had the approval of the local research ethics committee, and all patients had given written informed consent prior to study inclusion.

Table 1 Details of subjects who participated in the study

\begin{tabular}{|c|c|c|c|c|}
\hline & Sex & Age & $\begin{array}{l}\text { Body mass } \\
\text { index (BMI) }\end{array}$ & Procedure \\
\hline pat 34 & $\mathrm{~F}$ & 46 & 28.5 & Hysterectomy \\
\hline pat 36 & $\mathrm{~F}$ & 50 & $23 \cdot 3$ & Hysterectomy \\
\hline pat 39 & $\mathrm{~F}$ & 54 & $39 \cdot 7$ & Hysterectomy \\
\hline pat 41 & $\mathrm{~F}$ & 29 & $26 \cdot 2$ & Hysterectomy \\
\hline pat 43 & $\mathrm{~F}$ & 45 & $28 \cdot 8$ & Hysterectomy \\
\hline Mean & & $44 \cdot 8$ & $29 \cdot 3$ & \\
\hline S.D. & & $9 \cdot 5$ & $6 \cdot 2$ & \\
\hline
\end{tabular}

\section{Glucocorticoid treatment}

Confluent SC and OM preadipocytes were treated with $100 \mathrm{nM}$ F for $24 \mathrm{~h}$ in serum-free DMEM/F12 media. In control cells, F was omitted.

\section{RNA isolation}

Total RNA was extracted from primary cultures using TriReagent (Sigma). Total RNA was extracted from five confluent primary cultures of human SC and OM preadipocytes treated with or without $100 \mathrm{nM}$ F. Total RNA was treated with DNaseI to remove any genomic DNA contamination (DNaseI, Invitrogen) and its quantity and quality were assessed spectrophotometrically at $\mathrm{OD}_{260 / 280}$ and by electrophoresis on 1\% agarose gel.

\section{Affymetrix microarray experiments}

All experiments were performed using Affymetrix human HgU133A and HgU133B oligonucleotide array set, as described at http://www.affymetrix.com/ products/arrays/specific/hgu133.affyx and complied with Minimum Information About a Microarray Experiment (MIAME) standard. Total RNA was used to prepare biotinylated-target RNA with minor modifications from the manufacturer's recommendations (http://www. affymetrix.com/support/technical/manual/expression_manual.affx). Briefly, $10 \mu \mathrm{g}$ mRNA (pool of $2 \mu \mathrm{g}$ total RNA from each cell preparation) were used to generate first-strand cDNA by using a T7-linked oligo $(\mathrm{dT}$ ) primer (SuperScirpt Double Stranded cDNA Synthesis Kit, Invitrogen). After second-strand synthesis, in vitro transcription was performed with biotinylated UTP and CTP (Enzo Life Sciences, Farmingdale, NY, USA), resulting in approximately 100 -fold amplification of RNA. A complete description of procedures is available at http://bioinf.picr.man.ac.uk/mbcf/downloads/GeneChip_Target_Prep_Protocol_CRUK_v_2. pdf. The target cDNA generated from each sample was processed as per manufacturer's recommendation using an Affymetrix GeneChip Instrument System (http:// www.affymetrix.com/support/technical/manual/ expression_manual.affx). Briefly, spike controls were added to $15 \mu \mathrm{g}$ fragmented cDNA before overnight hybridisation. Arrays were then washed and stained with streptavidin-phycoerythrin, before being scanned on an Affymetrix GeneChip scanner. A complete description of these procedures is available at http://bioinf.picr. man.ac.uk/mbcf/downloads/GeneChip_Hyb_Wash_ Scan_Protocol_v_2_web.pdf. Additionally, quality and amount of starting RNA were confirmed using an agarose gel. After scanning, array images were assessed by eye to confirm scanner alignment and the absence of significant bubbles or scratches on the chip surface. $3^{\prime} /$ $5^{\prime}$ ratios for glyceraldehyde-3-phosphate dehydrogenase 
$(\mathrm{GAPDH})$ and $\beta$-actin were confirmed to be within acceptable limits $(0 \cdot 96-1 \cdot 14)$, and BioB spike controls were found to be present on all chips, with BioC, BioD and CreX also present in increasing intensity. When scaled to a target intensity of 100 , scaling factors for all arrays were within acceptable limits $(0 \cdot 8-1 \cdot 1)$, as were background, $Q$ values and mean intensities.

\section{Microarray data analysis}

Data from absolute and comparison files ( $\mathrm{F}$ treated versus control) in SC and OM preadipocytes were normalised and analysed using Gene Expression Pattern Analysis Suite $2 \cdot 0$ software (http://gepas.bioinfo.cipf.es). Methods used: background correction: Robust Multiarray Analysis (RMA); normalisation: quantiles; Perfect Match (PM) correction: pmonly; summary: medianpolish (http://gepas.bioinfo.cipf.es/cgi-bin/tools). A total of 22283 (U133A) and 22645 (U133B) entries in comparison analysis were sorted out according to criteria: (1) genes with absent call in control and treated cell arrays were deleted; (2) genes with difference call of no change were deleted; (3) genes with absolute signal below 100 were eliminated; (4) genes with signal $\log$ ratio (SLR) below 1 for I (increase) or above $-1 \cdot 0$ for D (decrease) were deleted (arbitrary cut-off point of twofold change) and (5) expressed sequence tags (ESTs) and hypothetical protein entries were not analysed.

This filtering procedure generated two datasets: SC preadipocytes treated with $\mathrm{F}$ versus control and $\mathrm{OM}$ preadipocytes treated with $\mathrm{F}$ versus control. Genes were analysed according to their metabolic function, such as glucocorticoid metabolism, transcription factors, genes involved in growth arrest, extracellular matrix (ECM) modulation, adipocyte-specific genes, immune responses, glucose metabolism and metabolic enzymes using NetAffx Analysis Center (www.affymetrix.com).

\section{Reverse transcription}

Total RNA ( $1 \mu \mathrm{g})$ in total volume of $20 \mu \mathrm{l}$ was reverse transcribed using avian myeloblastosis virus reverse transcriptase (AMV-RT) and random hexamers according to manufacturer's protocol (Promega). Fifty nanograms of cDNA ( $1 \mu \mathrm{l}$ reverse transcriptase (RT) reaction) were used for real-time PCR to confirm the expression of ten genes.

\section{Real-time PCR}

To confirm that the Affymetrix DNA microarray accurately identified the gene expression changes, we carried out quantitative RT-PCR of ten genes with varying degree of change, using the Applied Biosystems 7700 Real-Time PCR System (PE Applied Biosystems,
UK). Briefly, PCRs were carried out in $25 \mu$ l volumes on 96 -well plates, in a reaction buffer containing $2 \times$ TaqMan Universal PCR Master Mix. All reactions were singleplexed with the housekeeping gene 18S rRNA on the same plate, provided as a preoptimised control probe (PE Biosystems, Warrington, UK), enabling data to be expressed in relation to an internal reference, to allow for differences in RT efficiency. Measurements were carried out at least three times for each sample. All target gene probes were labelled with FAM, and the housekeeping gene with VIC. Reactions were as follows: $50{ }^{\circ} \mathrm{C}$ for $2 \mathrm{~min}, 95^{\circ} \mathrm{C}$ for $10 \mathrm{~min}$; then 44 cycles of $95^{\circ} \mathrm{C}$ for $15 \mathrm{~s}$ and $60^{\circ} \mathrm{C}$ for $1 \mathrm{~min}$. According to the manufacturer's guidelines, data were expressed as Ct values (the cycle number at which logarithmic PCR plots cross a calculated threshold line) and used to determine $\Delta \mathrm{Ct}$ values $(\Delta \mathrm{Ct}=\mathrm{Ct}$ of the target gene minus Ct of the housekeeping gene). To exclude potential bias due to averaging data, which had been transformed through the equation $2^{-\Delta \Delta \mathrm{Ct}}$ to give a fold change in gene expression, all statistics were performed with $\Delta \mathrm{Ct}$ values. Five sequences of primers and probes used for real-time PCR were designed using PrimerExpress software (Applied Biosystems, UK) and shown in Table 2. Five other genes; IL-6, IRS2, AGTR1, APOD and FABP4 were validated using commercially available Assay on Demand (Applied Biosystems, Applera, UK). Inter-patient and site differences of gene expressions were tested using individual cDNA preparation. These confirmed the same pattern of change as pooled cDNA used for Affymetrix arrays (data not shown).

\section{Statistical analysis}

In comparison analysis where baseline array were the control cells, statistical significance of signal log ratio (SLR; quantitative measure of the relative change in transcript abundance) was calculated. The Wilcoxon's signed rank test was used to compute change $P$ value for each probe set. The $P$ values range in scale from 0.0 to 1.0 and provide the likelihood of change and direction. $P$ values close to $0 \cdot 0(<0 \cdot 001)$ and $1 \cdot 0(>0 \cdot 998)$ were used for significant increase and significant decrease respectively (detailed information can be found in GeneChip Expression Analysis, Data Analysis Fundamentals, Affymetrix). For quantitative RT-PCR of the gene validation, statistical software (SPSS for Windows 11.5, SPSS, Inc., UK) was used for statistical analysis. Data are presented as mean values with standard error and $P$ value of $<0.05$ was accepted as statistically significant.

\section{Results}

We segregated genes of known function into three groups (Fig. 1): (a) SC specific - 43 upregulated and 21 


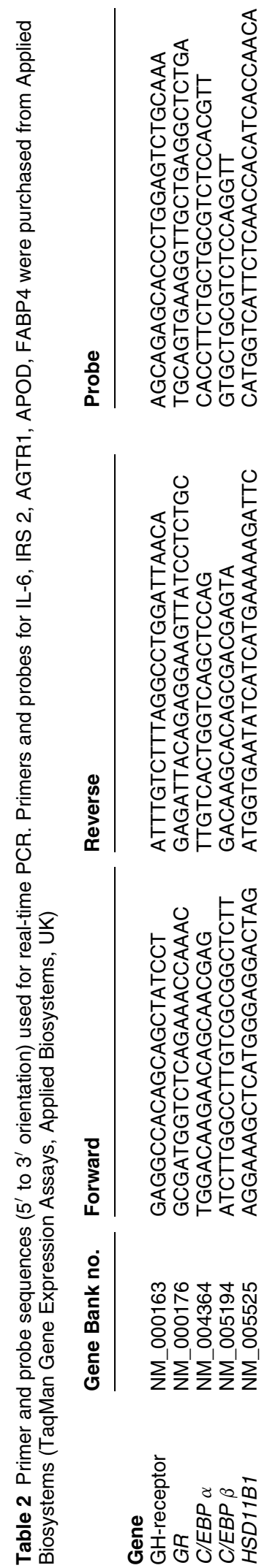

Journal of Molecular Endocrinology (2006) 37, 327-340

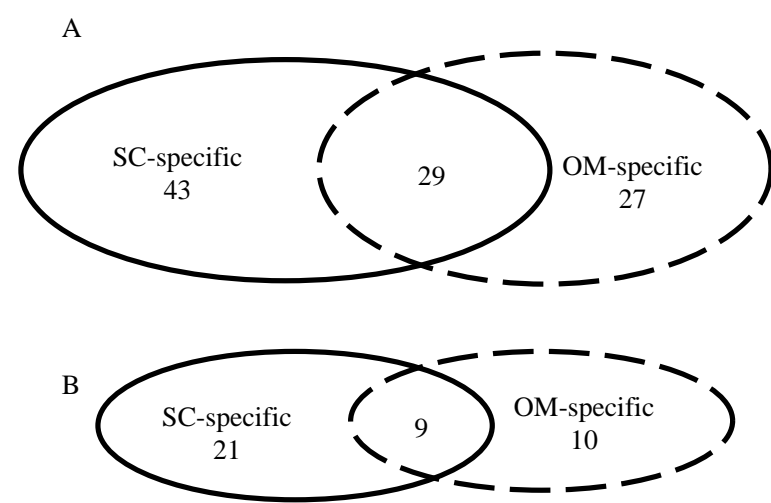

Figure 1 Number of genes with $(A)$ increased or $(B)$ decreased expression ( $\geq$ twofold) after $24 \mathrm{~h}$ cortisol $(\mathrm{F})$ treatment in SC, OM preadipocytes or in both adipose depots (adipose specific).

downregulated; (b) OM specific - 27 upregulated and 10 downregulated and (c) adipose specific - 29 upregulated and 9 downregulated in both SC and OM depots. The list of genes with their symbol, GeneBank accession number, description, fold change and function is shown in Table 3 (for increased expression) and Table 4 (for decreased expression).

\section{SC preadipocytes}

Genes that were upregulated by cortisol included those associated with negative regulation of cell growth (BTG1, PMP22, CD9, RAI2 and CUGBO2) and apoptosis-related proteins (e.g. CDO1, AMIGO2, CFLAR and CUGBP2) as well as genes involved in cell matrix rearrangements (e.g. CHL1, DPT, ABMLIM, PRELP and KIAA1011; Table 2).

Three transcription factors linked to cell growth, $\mathrm{C} / \mathrm{EBP} \alpha$, FOS (part of the AP-1 complex) and GFB were upregulated $2 \cdot 0-, 2 \cdot 2-$ and $2 \cdot 1$-fold (respectively). Additionally, a number of genes linked to lipid metabolism were upregulated - FACL2, LPL and $A P O B$. Significant upregulation of DF (adipsin), FABP4 and AGTR1 was also seen in SC preadipocytes, changes that were absent in OM cells. Expression levels of three of these genes $(C / E B P \alpha, F A B P 4$ and AGTR1) as well as $\mathrm{C} / \mathrm{EBP} \beta$ and glucocorticoid receptor (GR) were validated by real-time PCR (Figs 2-4).

A number of genes associated to G-protein coupled receptor signalling (EDNRB, GPRC5B, RABGAP1 and TM7SF1) and calcium action (ITPR1 and SPARCL1) were upregulated in depot-specific way (Table 3).

Genes that were specifically decreased in SC adipose stromal cells following incubation with cortisol (Table 4) included those positively regulating cell proliferation (VEGF and WARS), oncogenes (ENPP2), anti-apoptotic $(O X T R)$. Interestingly, in SC preadipocytes F-treatment decreased expression of two genes 
Table 3 Overview of the genes that were significantly increased after $24 \mathrm{~h} 100 \mathrm{nM}$ cortisol treatment $(\mathrm{F})$ compared to control (ctr) in subcutaneous (SC) omental (OM) preadipocytes or both fat deposits. Abbreviations are given

Acc no.

SC

Gene

Symbol

SC specific (fold increase)

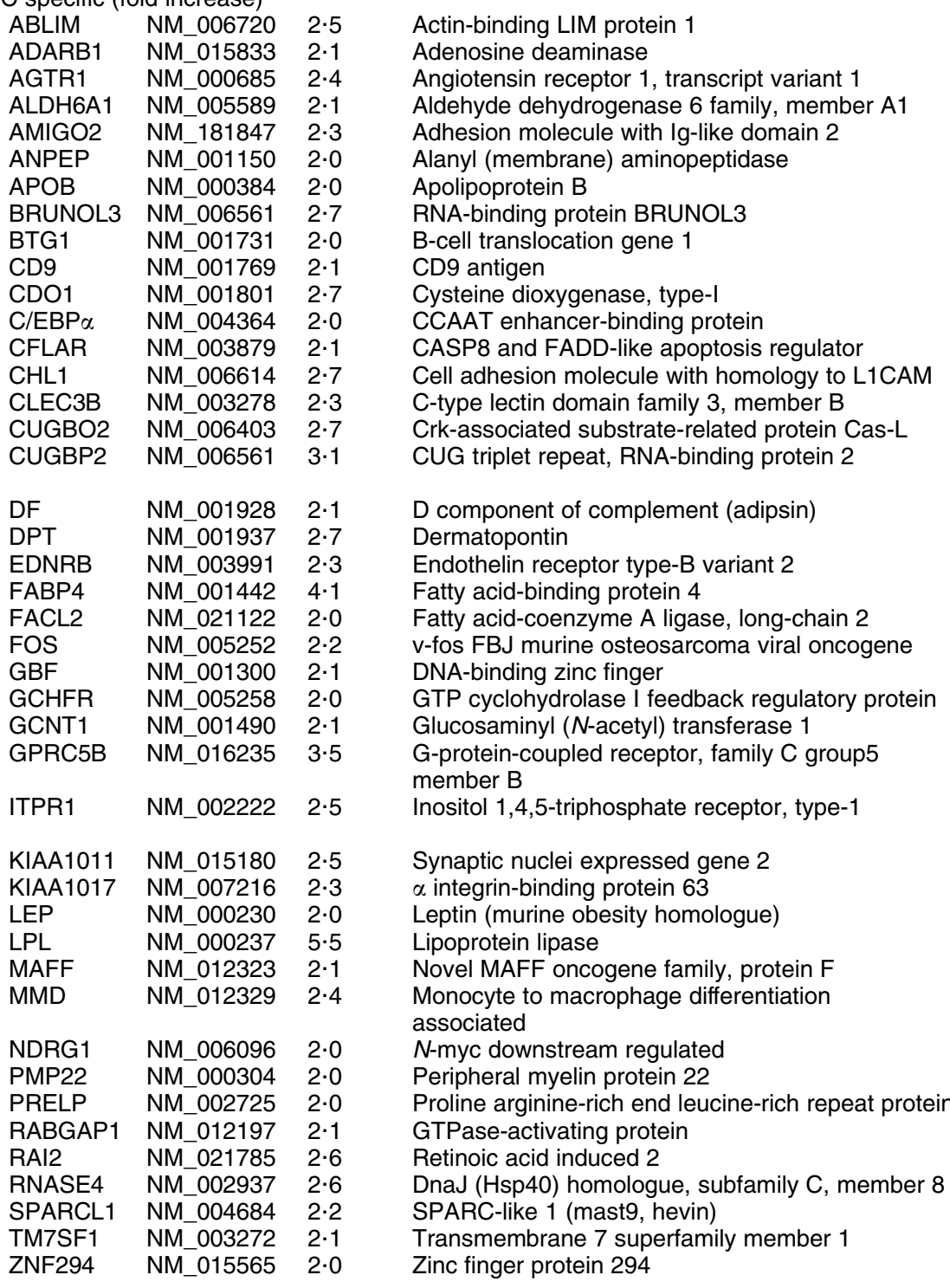

Function

Cytoskeletal protein

RNA processing

Renin/angiotensin system

Oxidative decarboxylation

Anti-apoptotic

Metabolism of regulatory peptides

Metabolism (lipid)/transport

RNA processing

Anti-proliferative

Cell growth

Apoptosis-related protein

Transcription factor/growth arrest

Anti-apoptotic

Cell adhesion

Plasminogen-binding protein

Cell growth/cell cycle

RNA processing/apoptosis-related protein

Adipose-specific peptide

Cell adhesion

G-protein-coupled receptor signalling

Adipose-specific peptide

Metabolism (lipids)

Cell proliferation/transcription factor

Transcription factor (anti-oncogene)

Metabolism (nitric oxide biosynthesis)

$\mathrm{N}$-acetyl-glucosaminyl transferase

G-protein-coupled receptor signalling

$\mathrm{Ca}^{++}$mobilisation from endoplasmic reticulum

Cytoskeletal protein

Metabolism (organelle biogenesis)

Adipose-specific peptide

Metabolism (lipids)

Protooncogene

Macrophage-specific gene

Macrophage-specific gene

Cell growth (negative)

Extracellular matrix (ECM) protein

G-protein-coupled receptor signalling

Cell growth

Ribonuclease

Calcium binding

G-protein-coupled receptor signalling

Transcription factor

Acc no.

OM Gene

Function

Symbol

OM specific (fold increase)

ABC1 NM 005502

ADM NM_001124 2.0

AKAP2 NM $007203 \quad 2 \cdot 1$

AKR1C1 NM_001353 $2 \cdot 2$

ALCAM NM $001627 \quad 2 \cdot 1$

ALDH1 NM_000689 2.4

AOX1 NM_001159 3.0

ARHGAP6 NM $013427 \quad 2 \cdot 0$

ATP-binding cassette, subfamily A member1

Adrenomedullin (ADM)

A kinase (PRKA) anchor protein 2

Aldo-keto reductase family 1 , member $\mathrm{C} 1$

Activated leucocyte cell adhesion molecule

Aldehyde dehydrogenase 1

Aldehyde oxidase 1

GTPase-activating protein 6
Steroid metabolism/transport

Electrolyte homeostasis (secreted)

Scaffold protein (kinase)

Metabolism (progesterone)

Cell adhesion

Metabolism (alcohol)

Metabolism (aldehyde oxidation)

GTPase activator 
Table 3 Continued

\begin{tabular}{|c|c|c|c|c|c|}
\hline & Acc no. & OM & \multicolumn{2}{|l|}{ Gene } & Function \\
\hline CITED2 & NM_006079 & $2 \cdot 1$ & \multicolumn{2}{|c|}{ GluAsp-rich carboxy-terminal domain, 2} & Transcription factor \\
\hline DIAPH2 & NM_006729 & $2 \cdot 0$ & \multicolumn{2}{|c|}{ Diaphanous (Drosophila, homologue) 2} & Cell differentiation \\
\hline EDG2 & NM_001401 & $2 \cdot 3$ & \multicolumn{2}{|c|}{$\begin{array}{l}\text { Lysophosphatidic acid G-protein-coupled } \\
\text { receptor } 2\end{array}$} & G-protein-coupled receptor signalling \\
\hline FMO2 & NM_001460 & $2 \cdot 4$ & \multicolumn{2}{|c|}{ Flavin-containing monooxygenase 2} & Metabolism ( $N$-oxidation of alkylamines) \\
\hline FN & NM_002026 & $2 \cdot 3$ & \multicolumn{2}{|c|}{ Migration stimulation factor MSF-FN70 } & Immune response/ECM protein \\
\hline F0X01A & NM_002015 & $2 \cdot 3$ & \multicolumn{2}{|c|}{ Forkhead box 01A } & Transcription factor \\
\hline GABRA2 & NM_000810 & $2 \cdot 1$ & \multicolumn{2}{|c|}{$\gamma$-aminobutyric acid A receptor $\alpha 5$} & Transport channel (chloride) \\
\hline GAS1 & NM_002048 & $2 \cdot 4$ & \multicolumn{2}{|c|}{ Growth arrest-specific 1} & Cell proliferation (negative) \\
\hline HPS5 & NM_007216 & $2 \cdot 1$ & \multicolumn{2}{|c|}{$\alpha$-integrin-binding protein 63} & Organelle biogenesis \\
\hline HSD11B1 & NM_005525 & $3 \cdot 3$ & \multicolumn{2}{|c|}{ Hydroxysteroid $(11-\beta)$ dehydrogenase 1} & Metabolism (glucocorticoids) \\
\hline ID1 & NM_002165 & $2 \cdot 6$ & \multicolumn{2}{|c|}{ Inhibitor of DNA binding 1} & Transcription factor/cell growth (negatively) \\
\hline KIAA0992 & NM_016081 & $2 \cdot 0$ & \multicolumn{2}{|c|}{ Palladin (KIAA0992) } & Cell adhesion \\
\hline LAMA2 & NM_000426 & $2 \cdot 3$ & \multicolumn{2}{|c|}{ Laminin, $\alpha 2$} & ECM protein \\
\hline OPN3 & NM_014322 & $2 \cdot 1$ & \multicolumn{2}{|c|}{ Opsin 3 (encephalopsin) } & G-protein-coupled receptor signalling \\
\hline PDE1A & NM_005019 & $2 \cdot 0$ & \multicolumn{2}{|c|}{ Phosphodiesterase 1A, calmodulin dependent } & Cyclic nucleotide phosphodiesterase \\
\hline PDGFD & NM_025208 & $2 \cdot 1$ & \multicolumn{2}{|c|}{ Platelet-derived growth factor D } & Proliferation/growth factor \\
\hline PIK3R1 & NM_181523 & $2 \cdot 0$ & \multicolumn{2}{|c|}{ Phosphoinositide-3-kinase (p85 $\alpha$ ) } & Insulin receptor signalling \\
\hline SRPX & NM_006307 & $2 \cdot 3$ & \multicolumn{2}{|c|}{ Sushi-repeat-containing protein, $\mathrm{X}$ chromosome } & Cell adhesion \\
\hline WISP1 & NM_003882 & $2 \cdot 1$ & \multicolumn{2}{|c|}{ WNT1-inducible-signalling pathway protein 1} & Wnt receptor signalling/cell proliferation \\
\hline & Acc no. & SC & OM & Gene & Function \\
\hline Symbol & & & & & \\
\hline Adipose sp & (fold increase) & & & & \\
\hline ADAMTS1 & NM_006988 & $5 \cdot 7$ & $2 \cdot 0$ & $\begin{array}{l}\text { Metalloproteinase with thrombospondin } \\
\text { type-1 }\end{array}$ & Cell proliferation (negative) \\
\hline $\mathrm{ADH} 2$ & NM_000668 & $4 \cdot 2$ & $11 \cdot 5$ & Alcohol dehydrogenase $\beta 1$ & Metabolism (ethanol) \\
\hline APOD & NM_001647 & $5 \cdot 1$ & $2 \cdot 4$ & Apolipoprotein D & Metabolism (lipids) \\
\hline C10orf10 & NM_007021 & $4 \cdot 0$ & $4 \cdot 9$ & $\begin{array}{l}\text { Decidual protein induced by } \\
\text { progesterone }\end{array}$ & $\begin{array}{l}\text { Unknown/increased expression } \\
\text { in fasting }\end{array}$ \\
\hline CD163 & NM_004244 & $3 \cdot 9$ & $3 \cdot 6$ & CD163 antigen & Immune response \\
\hline CDKN1C & NM_000076 & $2 \cdot 2$ & $2 \cdot 4$ & Cyclin-dependent kinase inhibitor 1C & Cell cycle (G1 phase arrest) \\
\hline CHST2 & NM_004267 & $2 \cdot 7$ & $2 \cdot 3$ & Carbohydrate sulphotransferase 2 & Immune response \\
\hline CPM & NM_001874 & $9 \cdot 1$ & $2 \cdot 5$ & Carboxypeptidase M & Immune response \\
\hline ENNRB & NM_000115 & $3 \cdot 9$ & $3 \cdot 0$ & Endothelin receptor type B, variant 1 & G-protein-coupled receptor signalling \\
\hline FBN2 & NM_001999 & $5 \cdot 0$ & $2 \cdot 5$ & $\begin{array}{l}\text { Fibrillin } 2 \text { (congenital contractural } \\
\text { arachnodactyly) }\end{array}$ & ECM protein \\
\hline GHR & NM_000163 & $3 \cdot 0$ & $3 \cdot 0$ & Growth hormone receptor & Insulin/IGF-signalling pathway \\
\hline GLUL & NM_002065 & $2 \cdot 5$ & $2 \cdot 1$ & $\begin{array}{l}\text { Glutamate-ammonia ligase (glutamine } \\
\text { synthase) }\end{array}$ & Metabolism (glutamate/nitrogen) \\
\hline GPX3 & NM_002084 & $5 \cdot 6$ & $9 \cdot 3$ & Glutathione peroxidase 3 (plasma) & Metabolism (anti-oxidative) \\
\hline HSPA2 & NM_021979 & $3 \cdot 1$ & $2 \cdot 4$ & Heat shock $70 \mathrm{kD}$ protein 2 & Chaperone protein (glucose regulated) \\
\hline HXL1 & NM_021958 & $2 \cdot 4$ & $2 \cdot 2$ & Drosophila-like homeo box 1 & Transcription factor \\
\hline IMPA2 & NM_014214 & $2 \cdot 8$ & $2 \cdot 5$ & $\begin{array}{l}\text { Inositol(myo)-1(or 4)-monophos } \\
\text { phatase } 2\end{array}$ & Phosphatidyl inositol-signalling pathway \\
\hline IRS2 & NM_003749 & $3 \cdot 3$ & $2 \cdot 2$ & Insulin receptor substrate 2 & Metabolism (glucose metabolism) \\
\hline LDO3 & NM_018640 & $3 \cdot 7$ & $2 \cdot 3$ & LIM domain only 3 & Transcription factor \\
\hline MAOA & NM_000240 & $5 \cdot 1$ & $4 \cdot 5$ & Monoamine oxidase A & $\begin{array}{l}\text { Metabolism (neurotransmitters } \\
\text { catabolism) }\end{array}$ \\
\hline MGP & NM_000900 & $3 \cdot 5$ & $2 \cdot 6$ & Matrix Gla protein & ECM protein \\
\hline NRCAM & NM_005010 & $2 \cdot 4$ & $2 \cdot 7$ & Neuronal cell adhesion molecule & Cell adhesion \\
\hline PDK4 & NM_002612 & $2 \cdot 4$ & $2 \cdot 0$ & $\begin{array}{l}\text { Pyruvate dehydrogenase kinase, isoen- } \\
\text { zyme } 4\end{array}$ & - Metabolism (glucose metabolism) \\
\hline REV3L & NM_002912 & $2 \cdot 2$ & $3 \cdot 3$ & $\begin{array}{l}\text { REV3-like, catalytic subunit of DNA } \\
\text { polymerase } \zeta\end{array}$ & Transcription factor \\
\hline RGC32 & NM_014059 & $11 \cdot 9$ & $6 \cdot 0$ & RGC32 protein & Cell proliferation (growth arrest) \\
\hline RNASE4 & NM_002937 & $2 \cdot 3$ & $2 \cdot 0$ & Ribonuclease, RNase A family, 4 & Ribonuclease activity \\
\hline SAA2 & NM_030754 & $2 \cdot 1$ & $3 \cdot 7$ & Serum amyloid A2- $\alpha$ & Immune response \\
\hline STC2 & NM_003714 & $2 \cdot 0$ & $2 \cdot 0$ & Stanniocalcin 2 & Calcium and phosphate homeostasis \\
\hline TSC22D3 & NM_198057 & $4 \cdot 4$ & $3 \cdot 3$ & $\delta$ sleep-inducing peptide, immunoreactor & r Transcription factor \\
\hline ZNF145 & NM_006006 & $6 \cdot 4$ & $2 \cdot 8$ & Zinc finger protein 145 & Transcription factor/growth arrest \\
\hline
\end{tabular}


Table 4 Overview of the genes that were significantly decreased after $24 \mathrm{~h} 100 \mathrm{nM}$ cortisol treatment (F) compared to control (ctr) in subcutaneous (SC), omental (OM) preadipocytes or both fat deposits. Abbreviations are given

Acc no.

SC

Gene

Symbol

SC specific (fold decrease)

$\begin{array}{lll}\text { C5orf13 } & \text { NM_004772 } & 2 \cdot 4 \\ \text { CDH2 } & \text { NM_001792 } & 2 \cdot 7 \\ \text { CRABP2 } & \text { NM_001878 } & 2 \cdot 2 \\ \text { DKFZP564I1922 } & \text { AF245505 } & 2 \cdot 8 \\ \text { ENPP2 } & \text { NM_006209 } & 2 \cdot 1 \\ & & \\ \text { FZD7 } & \text { NM_003507 } & 3 \cdot 5 \\ & & \\ \text { GATA6 } & \text { NM_005257 } & 2 \cdot 0 \\ \text { IGFBP5 } & \text { NM_000599 } & 2 \cdot 4 \\ \text { IL-6 } & \text { NM_000600 } & 2 \cdot 3 \\ \text { LDB2 } & \text { NM_001290 } & 5 \cdot 0 \\ \text { NOV } & \text { NM_002514 } & 2 \cdot 9 \\ \text { OXTR } & \text { NM_000916 } & 2 \cdot 0 \\ \text { PRSS23 } & \text { NM_007173 } & 2 \cdot 2 \\ \text { PSA } & \text { NM_021154 } & 2 \cdot 0 \\ \text { PSG5 } & \text { NM_002781 } & 2 \cdot 6 \\ \text { SERPINE2 } & \text { NM_006216 } & 3 \cdot 0 \\ & & \\ \text { SFRP4 } & \text { NM_003014 } & 3 \cdot 3 \\ \text { SGNE1 } & \text { NM_003020 } & 2 \cdot 1 \\ \text { VEGF } & \text { NM_003376 } & 2 \cdot 0 \\ \text { WARS } & \text { NM_004184 } & 2 \cdot 4 \\ \text { ZNF423 } & \text { NM_015069 } & 2 \cdot 1\end{array}$

Function

Chromosome 5 open reading frame 13

$N$-cadherin .1

Cellular retinoic acid-binding protein 2

Adlican DKFZP564l1922 protein

Ectonucleotide pyrophosphatasephosphodiesterase 2

frizzled (Drosophila) homologue 7

GATA-binding protein 6

Insulin-like growth factor-binding protein 5 Interleukin 6 (interferon, $\beta 2$ )

LIM domain binding 2

Nephroblastoma overexpressed gene

Oxytocin receptor

Protease, serine, 23

Phosphoserine aminotransferase

Pregnancy-specific $\beta$-1-glycoprotein 5

Nexin, plasminogen activator inhibitor type-1

Secreted frizzled-related protein 4

Secretory granule, neuroendocrine protein 1

Vascular endothelial growth factor

Tryptophanyl-tRNA synthetase

Zinc finger protein 423
Unknown

Cell adhesion protein

Retinoic acid action on cell differentiation Vascular endothelial growth

Oncogene activity/G-protein-coupled signalling

Wnt-receptor-signalling pathway

(receptor)

Transcription factor (proliferation/differentiation)

IGF signalling (cell growth)

Immune response/cytokine

Transcription factor

Cell growth

G-protein-coupled IP3 signalling

Protein degradation

Metabolism (amino acid synthesis)

Unknown

Serine protease inhibitor

Wnt-receptor-signalling pathway/differentiation

Facilitate active transport from ER

Cell proliferation (positive)/angiogenesis

Cell proliferation

Nucleic acid binding/developmental

\begin{tabular}{|c|c|c|c|c|c|}
\hline & Acc no. & OM & \multicolumn{2}{|c|}{ Gene } & Function \\
\hline \multicolumn{6}{|l|}{ Symbol } \\
\hline CCL11 & NM_002986 & $4 \cdot 5$ & \multicolumn{2}{|c|}{$\begin{array}{l}\text { Adhesion molecule with Ig-like domain } 2 \\
\text { Small inducible cytokine subfamily A member } \\
11\end{array}$} & Immune response \\
\hline HAS2 & NM_005328 & $3 \cdot 0$ & \multicolumn{2}{|c|}{$\begin{array}{l}\text { Hyaluronan synthase } 2 \\
\text { Leukaemia inhibitory factor (LIF) }\end{array}$} & ECM protein \\
\hline NGFB & NM_002506 & $2 \cdot 0$ & \multicolumn{2}{|c|}{ Nerve growth factor, $\beta$ polypeptide } & Growth factor activity \\
\hline NPPB & NM_002521 & $2 \cdot 7$ & \multicolumn{2}{|c|}{ Natriuretic peptide precursor $B$} & Electrolyte homeostasis \\
\hline PRAD1 & M73554 & $2 \cdot 0$ & \multirow{2}{*}{\multicolumn{2}{|c|}{$\begin{array}{l}\text { bcl-1 cyclin D1 } \\
\text { Solute carrier family } 22 \text { member } 3\end{array}$}} & Cell cycle (G1/S) transition control \\
\hline SLC22A3 & NM_021977 & $3 \cdot 1$ & & & Monoamine transporter \\
\hline Smurf2 & NM_022739 & $2 \cdot 8$ & \multicolumn{2}{|c|}{ E3 ubiquitin ligase } & $\begin{array}{l}\text { Transforming growth factor } \beta \text { signalling } \\
\text { (negative)/protein catabolism }\end{array}$ \\
\hline ADAM12 & NM_003474 & $2 \cdot 7$ & $2 \cdot 4$ & Metalloproteinase domain 12 transcript 1 & 1 Metalloprotease/cell-cell interaction \\
\hline C1orf24 & NM_022083 & $2 \cdot 4$ & $2 \cdot 1$ & Chromosome 1 open reading frame 24 & Cell growth (positive)(?) \\
\hline DACT1 & NM_016651 & $2 \cdot 6$ & $2 \cdot 1$ & $\begin{array}{l}\text { Hepatocellular carcinoma novel gene } 3 \\
\text { protein }\end{array}$ & Wnt-signalling pathway \\
\hline DSCR1 & NM_004414 & $3 \cdot 1$ & $2 \cdot 7$ & Down syndrome critical region gene 1 & Transcription factor \\
\hline FGF2 & NM_002006 & $2 \cdot 7$ & $2 \cdot 2$ & Fibroblast growth factor 2 (basic) & Cell proliferation (positive) \\
\hline GDF15 & NM_004864 & $2 \cdot 1$ & $2 \cdot 0$ & Prostate differentiation factor 1 & Tissue differentiation/growth factor \\
\hline RGS4 & NM_005613 & $2 \cdot 4$ & $4 \cdot 3$ & Regulator of G-protein signalling 4 & $\begin{array}{l}\text { G-protein couped receptor signalling } \\
\text { pathway }\end{array}$ \\
\hline TNFAIP6 & NM_007115 & $2 \cdot 8$ & $2 \cdot 0$ & $\begin{array}{l}\text { Tumour necrosis factor, } \alpha \text {-induced } \\
\text { protein } 6\end{array}$ & Immune response \\
\hline TRIB3 & NM_021158 & $2 \cdot 4$ & $2 \cdot 4$ & Kinase domains-containing protein & Cell growth (positive) \\
\hline
\end{tabular}



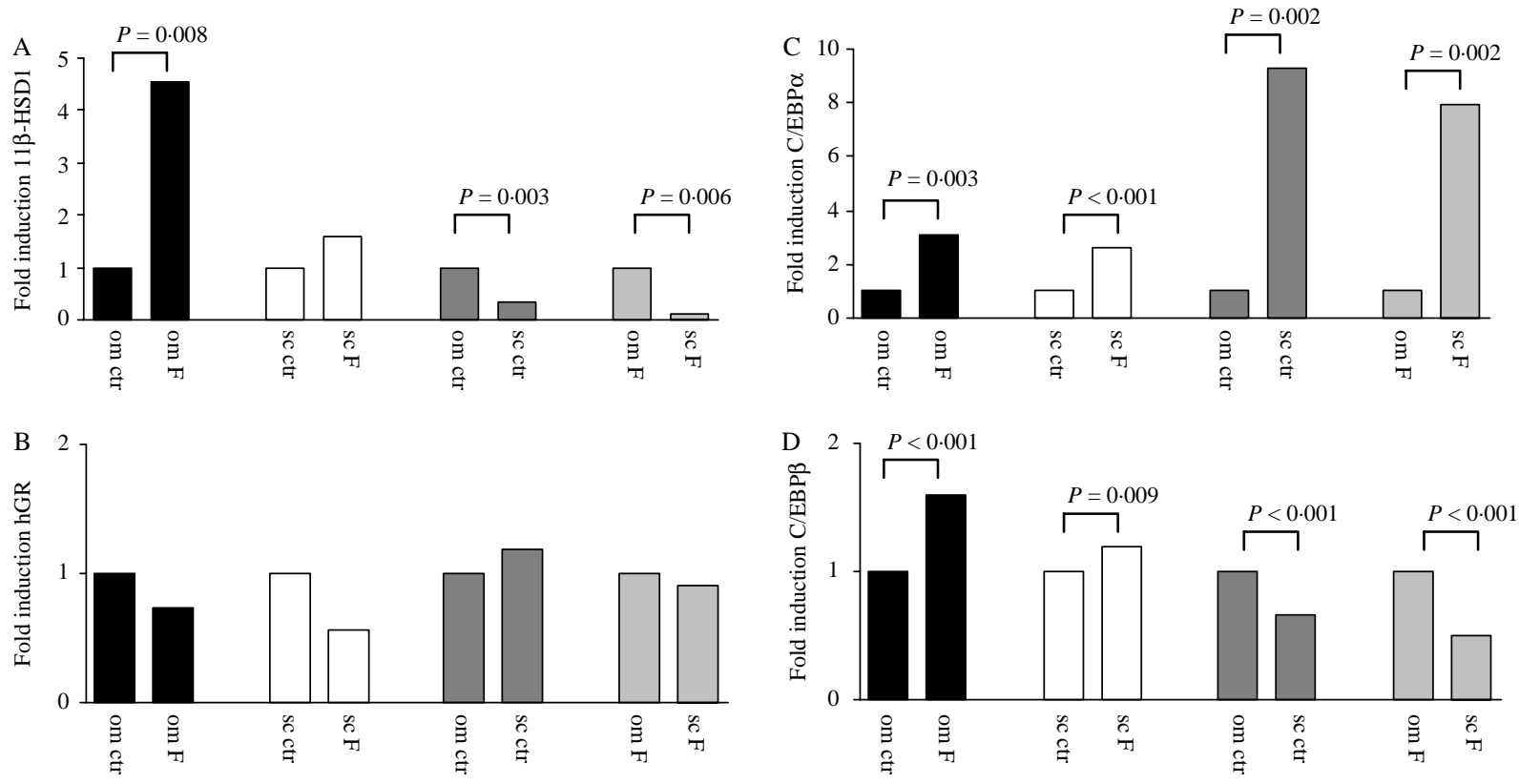

Figure 2 Fold change in mRNA expression in OM and SC preadipocytes after $24 \mathrm{~h}$ cortisol (100 nM F) or control (ctr) treatment

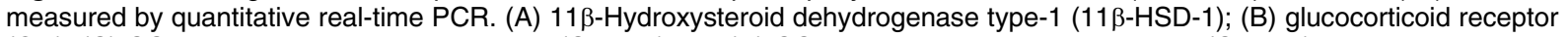
(GR); (C) CCAAT enhancer-binding protein $\alpha(\mathrm{CEBP} \alpha)$ and (D) CCAAT enhancer-binding protein $\beta$ (CEBP $\beta)$.

associated with Wnt-signalling pathways (FZD7 and SFRP4; 3·5- and 3·3-fold respectively; Fig. 3).

F-treatment significantly decreased IL-6 expression only in SC preadipocytes (2.3-fold), however, the absolute signal of IL-6 was much higher in OM preadipocytes. This finding was confirmed and validated by real-time PCR (Fig. 3).

The expression levels of two transcription factors, LDB2 and GATA6, were lowered by cortisol $(5 \cdot 0-$ and 2.0-fold respectively). Additionally, SGNE1 (associated
A

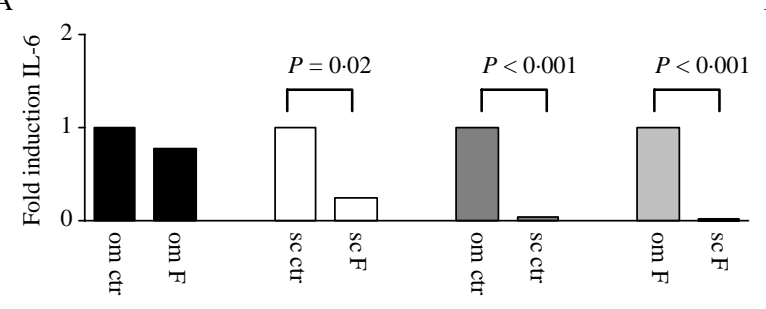

$\mathrm{B}$

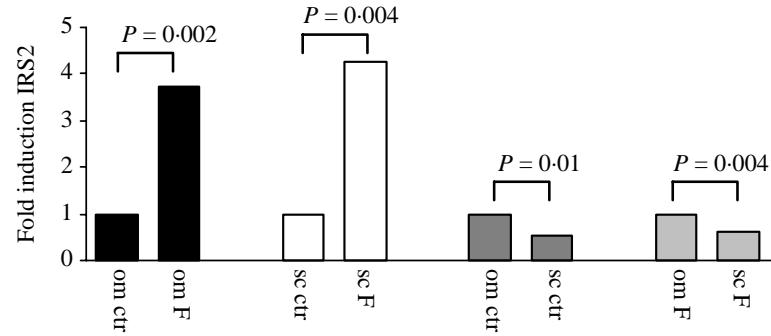

$\mathrm{C}$

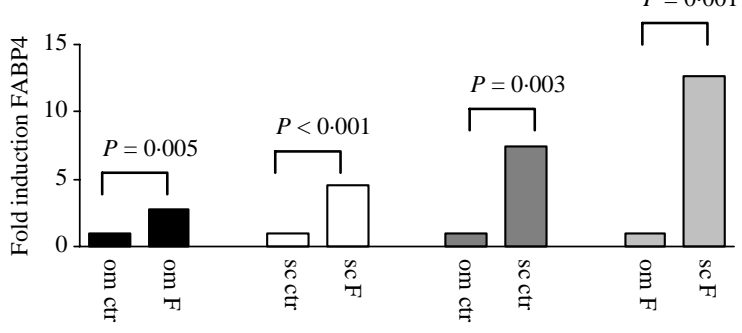

$\mathrm{D}$

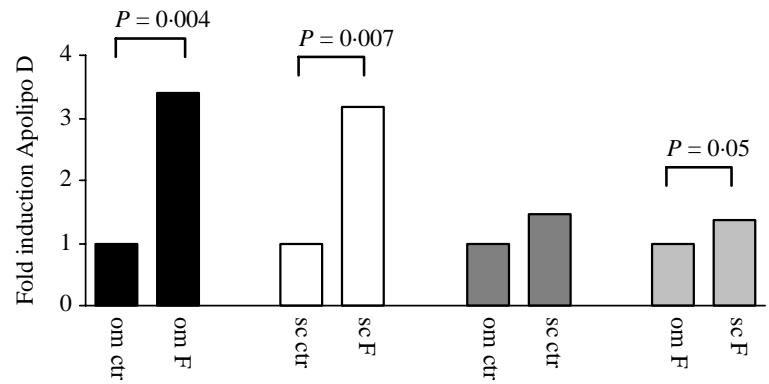

Figure 3 Fold change in mRNA expression in OM and SC preadipocytes after $24 \mathrm{~h}$ cortisol (100 nM F) or control (ctr) treatment measured by quantitative real-time PCR. (A) Interleukin 6 (IL-6); (B) fatty acid-binding protein 4 (FABP4); (C) insulin receptor substrate 2 (IRS2) and (D) apolipoprotein D (Apolipo D). 

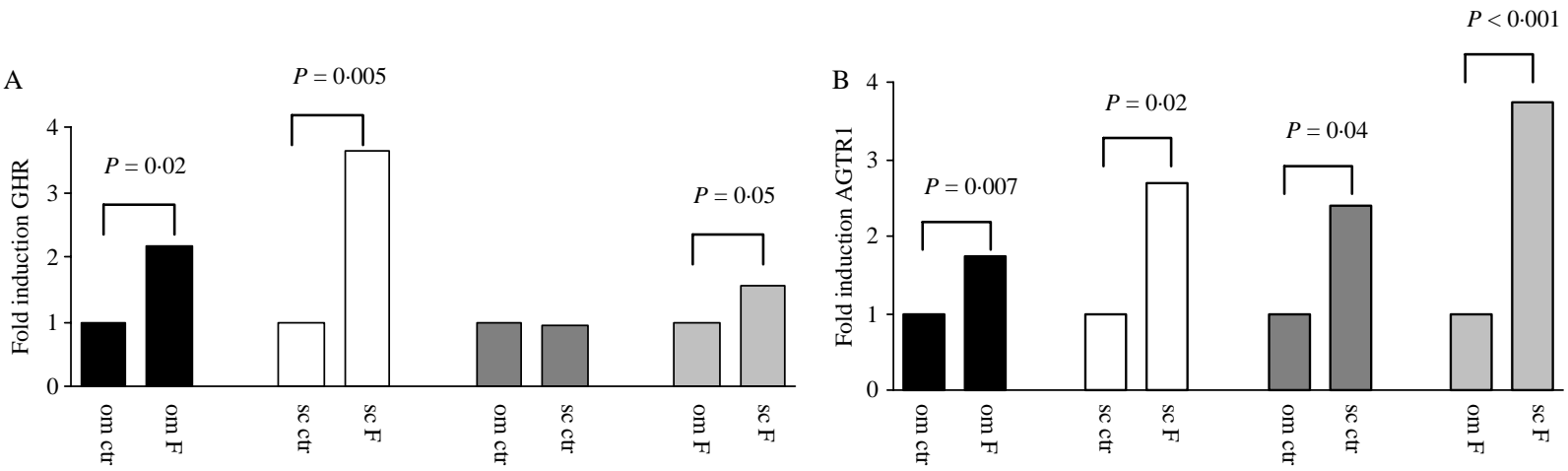

Figure 4 Fold change in mRNA expression in OM and SC preadipocytes after $24 \mathrm{~h}$ cortisol (100 $\mathrm{nM} \mathrm{F}$ ) or control (ctr) treatment measured by quantitative real-time PCR. (A) Growth hormone receptor (GHR) and (B) angiotensin receptor 1 (AGTR1).

with active transport from the ER) and IGFBP5 (IGFsignalling pathway) were downregulated by $\mathrm{F}(2 \cdot 1-$ and 2-4-fold).

\section{OM preadipocytes}

Several genes were specifically upregulated by cortisol but only in OM depots: GAS1, PDGFD and ID1 negatively associated with cell growth $(2 \cdot 4-, 2 \cdot 1-$ and $2 \cdot 6$-fold respectively), positively with cell differentiation (DIAPH2, 2.0-fold), and ECM proteins (LAMA2, AKAP2, ACKLAM, SPRX and KIAA0992). A number of metabolic enzymes were upregulated in OM cells only: ALDH1 (2·4-fold), AOX1 (3・0-fold) and AKR1C1 (2-1-fold). Interestingly, among metabolic enzymes involved in glucocorticoid metabolism, HSD11B1 was upregulated in OM preadipocytes $(3 \cdot 3$-fold), encoding $11 \beta$-HSD1 enzyme. This was confirmed using real-time PCR (Fig. 2). The gene encoding adrenomedullin (ADM) was upregulated $2 \cdot 0$-fold. Fibronectin $(\mathrm{FN})$ involved in the immune response was upregulated in OM cells (2.3-fold) but not in SC cells. One member of Wnt-signalling pathway, WISP1, was upregulated in OM cells (2.1-fold) as well as two transcription factors, CITED2 and FOXO1A (2·1- and 2·3-fold respectively).

Downregulated OM-specific genes included PRADI (controlling G1/S transition) and ECM proteins (HAS2 and MMP1). A gene associated with transforming growth factor $\beta$ signalling (SMURF2) was $2 \cdot 8$-fold. Small inducible cytokine subfamily A, member 11 (CCL11) and leukaemia inhibitory factor involved in immune responses were downregulated $4 \cdot 5$ - and 2.2-fold respectively in $\mathrm{OM}$ cells. Interestingly, natriuretic peptide $\mathrm{B}(\mathrm{NPB})$, gene involved in electrolyte homeostasis and lipolysis in human adipocytes was decreased $2 \cdot 7$-fold by cortisol and was below detection levels in SC cells.

\section{Common adipose-specific genes}

Twenty-eight genes were upregulated by cortisol in both SC and OM depots, including those involved in cell cycle regulation and growth (CDKN1C, RGC32 and ADAMTS1), one associated with cell adhesion (NRCAM) and rearrangement of cell matrix (FBN2 and $M G P$ ). A number of transcription factors were upregulated in cells from both depots: HXL1, LDO3, TSC22D3, REV3L and ZFP145. Components of insulin-signalling pathway: IRS2, GHR, PDK4 and glucose-regulated chaperone protein (HSPA2) were significantly upregulated by cortisol in SC and OM preadipocytes as apolipoprotein $\mathrm{D}(\mathrm{ApoD})$ implicated in lipid metabolism (Table 3). IRS2 and GHR expression profiles were validated by real-time PCR (Figs 3 and 4).

In terms of genes related to the immune response, expression of CD163, CHST2 and CPM all increased in both depots. Plasma glutathione peroxidase 3 precursor (GPX3), catalyses the reduction of hydrogen peroxide, organic hydroperoxide and lipid peroxides, protecting cells against oxidative damage. It was expressed at very high levels in control SC cells and was significantly upregulated in both $\mathrm{SC}$ and $\mathrm{OM}$ depots by F. Additionally, genes encoding many metabolic enzymes like GLUL (glutamate/nitrogen metabolism), ADH2 (ethanol metabolism) and MAOA (neurotransmitters catabolism) were upregulated in preadipocytes from both depots (Table 3).

Most of the genes downregulated by cortisol in both SC and $\mathrm{OM}$ preadipocytes were associated with cell cycle control and proliferation/growth processes; e.g. FGF2, TRIB3 and oncogene (C1orf24). As expected, proinflammatory gene such as $\mathrm{TNF} \alpha$ induced protein 6 (TNFA1P6) was decreased by cortisol in both depots. Transcription factor DSCR1 was decreased in SC and OM cells (3·1- and 2·7-fold respectively). Cortisol treatment decreased expression of one component of Wnt-signalling pathway (DACT1) in SC and OM preadipocytes $(2 \cdot 6-$ and $2 \cdot 1$-fold respectively), Table 4 . 


\section{Discussion}

We have identified several glucocorticoid-regulated genes in human adipose tissue, many of which show site specificity between $\mathrm{OM}$ and SC depots that may contribute to the established predilection of glucocorticoids for visceral adiposity. Additionally, these candidates may be informative as we look towards an explanation for the basis of the deleterious distribution of visceral fat.

In terms of the GR itself, earlier studies had reported increased expression in $\mathrm{OM}$ adipose tissue when compared with SC fat (Bronnegard et al. 1990). Here, we show very similar levels of GR mRNA in preadipocytes of both depots and report that incubation with $\mathrm{F}$ for $24 \mathrm{~h}$ had no significant effect on GR expression in human SC or OM preadipocytes. By contrast, the study does confirm our earlier reports of increased expression of the 'prereceptor' regulator of GR action, the HSD11B1 gene which encodes the enzyme $11 \beta-$ hydroxysteroid dehydrogenase type-1 (11ß-HSD1) in OM compared with SC preadipocytes and significant upregulation of its expression by $\mathrm{F}$ only in $\mathrm{OM}$ sites (Bujalska et al. 1997). The enzyme 11ß-HSD2 was absent confirming previous observations (Bujalska et al. 1997). The explanation for the increased HSD11B1 expression in $\mathrm{OM}$ versus $\mathrm{SC}$ sites remains unclear. Rodent studies had indicated marked induction of expression by the transcription factors CCAAT enhancer-binding protein $\alpha(\mathrm{C} / \mathrm{EBP} \alpha$; Williams et al. 2000). However, in this human-based study $\mathrm{C} / \mathrm{EBP} \alpha$ expression was absent in $\mathrm{OM}$ preadipocytes and $\mathrm{C} /$ EBP $\beta$, whilst being highly expressed in SC and OM preadipocytes, was not regulated by $\mathrm{F}$. It seems unlikely based on these data that $\mathrm{C}$ /EBPs play a major role in the site-specific transcriptional regulation of HSD11B1 or GR in human preadipocytes.

\section{Growth arrest/extracellular matrix}

Whilst GCs provide a crucial signal for preadipocyte differentiation (Hauner et al. 1987), the first step defining adipogenesis is cell growth arrest (Ailhaud et al. 1989). This study looked comprehensively on the effect of GCs on genes associated with cell cycle control. We identified a number of genes such as CDKN1C, which overexpression caused complete cell arrest in G1 phase (Lee et al. 1995), and RGC32 negatively controlling cell growth (Badea et al. 1998) as novel GC-target genes in SC and OM preadipocytes. Furthermore, we found ADAMTS1, gene which disruption in knockout mice caused adipose tissue malformation (Shindo et al. 2000), being upregulated by GC-target in human preadipocytes together with downregulation of FGF2 providing positive proliferation signal (Kurokawa et al. 1987). We identified different sets of genes regulating cell growth in depot-specific manner. Only in $\mathrm{OM}$ cells, we see increased expression of GAS1 (involved in growth suppression) and decreased of PRAD1 (a G1 marker gene decreased by dexamethasone in airway smooth muscle cells (Fernandes et al. 1999)), but increased expression of BTG1 in SC cells. Our findings imply site-specific pathway of cell arrest in human preadipocytes.

Interestingly, downregulation of genes, FZD7 and SFRP4 associated with the Wnt-signalling pathway was observed only in SC preadipocytes while upregulation of WISP1, down-stream target of Wnt pathway in hepatocellular carcinoma cells (Cervello et al. 2004), was seen only in OM cells. Downregulation of Wnt pathway was recently shown to be crucial for the adipogenesis in mouse cell line (3T3L1; Bennett et al. 2002), however, its role in human preadipocytes still needs to be evaluated.

Preadipocyte growth arrest is accompanied by reorganisation of extracellular matrix (ECM; Gregoire et al. 1991). We found several novel GC-target genes associated with cell-cell adhesion proteins in human preadipocytes, e.g. FBN2, MGP and NRCAM. However, several ECM GC-target genes were site specific and their role in site-specific adipogenesis remains to be elucidated. For example, in SC cells, CLEC3B (tetranectin) was highly expressed and upregulated by $\mathrm{F}$ but below detection levels in OM cells. CHL1 ABLIM, dermatopontin (DPT) and PRELP were GC-target genes of the ECM upregulated only in SC cells. DPT, cartilage matrix component, was recently shown to be upregulated by dexamethasone in chondrogenic differentiation from human bone marrow mesenchymal stem cells (Derfoul et al. 2006). Conversely, expression of ALCAM, KIAA0992 (identified as risk factor for myocardial infarction; Shiffman et al. 2005) and SRPX was upregulated in OM cells.

Hereby, we demonstrate that GCs induce a sitespecific block on the cell cycle progression together with site-specific differences in ECM remodelling. These would indicate unique pathways of preadipocyte commitment to adipogenesis in these two human adipose tissue depots.

\section{Metabolic enzymes}

Human alcohol dehydrogenase 2 (ADH2) exhibits high activity for unsaturated and aromatic alcohols and aldehydes in the metabolism of noradrenaline, retinoids and lipid peroxidation thus plays an important role in detoxification in the liver, reviewed by Higuchi et al. (2004). This study revealed high ADH2 expression in human preadipocytes (much higher in SC than OM) and positive regulation by GCs in both adipose depots. Dexamethasone has been shown to upregulate ADH2 expression in the HepG2 cell line (Dong et al. 1988); 
however, ADH2 expression and its role in the human adipose tissue have not yet been elucidated. On the other hand, aldo-keto reductase family 1 , member C1 (AKR1C1), a major enzyme in progesterone metabolism was also highly expressed in $\mathrm{SC}$ and $\mathrm{OM}$ preadipocytes (again more in SC than $\mathrm{OM}$ ), but was only upregulated by GCs in OM preadipocytes. AKR1C1 has been shown to be expressed in human SC and OM adipose tissue (Blanchette et al. 2004) and positively correlated with visceral obesity. Our findings may provide an explanation for this correlation, since more cortisol is generated in $\mathrm{OM}$ tissue due to increased expression of $11 \beta-H S D 1$.

\section{Adipose-specific genes}

In keeping with previous findings (Masuzaki et al. 1995), leptin expression was undetectable in SC and OM preadipocytes; GCs increased its expression only in SC preadipocytes. It has been shown that $\mathrm{C} / \mathrm{EBP} \alpha$ upregulates human (Miller et al. 1996) leptin mRNA expression and we confirmed a parallel induction of leptin and $\mathrm{C} / \mathrm{EBP} \alpha$ by GCs in SC cells. Lipoprotein lipase, an early differentiation marker of adipogenesis has been shown to be expressed at higher levels and upregulated by GCs in SC human female adipose tissue (Fried et al. 1993), a pattern that was confirmed in preadipocytes in this study. In rat, insulin is required for the induction of early differentiation genes such as LPL (Gregoire et al. 1991), but we showed that a relatively short exposure to GCs to SC preadipocytes induced LPL expression without the requirement of insulin.

FABP4, product of the $a P 2$ gene, is regulated by dexamethasone in mouse 3T3L1 cells (Cook et al. 1988) as well as in differentiating preadipocytes from rat bone marrow (Atmani et al. 2003). This study verified FABP4 gene as a glucocorticoid-target gene but only in SC preadipocytes. Upregulation of $a P 2$ gene in response to GCs as well as transcription factors-binding sites for C/ EBP and c-fos (forming AP-1 complex) in the promoter region of mouse $a P 2$ gene was shown previously (Ross et al. 1990). Our findings, demonstrating increased expression of these two transcription factors together with FABP4 expression in SC preadipocytes, might reflect different sensitivity of human SC and OM preadipocytes to adipogenic effect of GCs.

ApoD is involved in cellular transport of small hydrophobic ligands, such as progesterone, cholesterol, pregnenolone, bilirubin and arachidonic acid but its exact role is still not known. ApoD was expressed at similar levels in SC and OM preadipocytes but these fat compartments responded differently to GC (upregulation $\mathrm{SC}>\mathrm{OM}$ ). On the other hand, ApoB, component for VLDL associated with type-2 diabetes and insulin resistance reviewed by Ginsberg et al. (2005) and increased risk of coronary heart disease (Despres 1998), was positively regulated only in SC cells. Although our finding provides evidence for glucocorticoid regulation of ApoB in human SC preadipocyte, its significance needs to be evaluated.

Natriuretic peptides have been shown to have a potent lipolytic effect in human adipocytes (Sengenes et al. 2000). Moreover, significantly reduced levels of NPB have been found in obese patients with heart failure (Mehra et al. 2004). Our finding shows NPB expression in OM preadipocytes as well as GC-target gene (but absent in SC) could provide a novel mechanism explaining the relationship between glucocorticoids, central obesity and heart failure. Moreover, increased expression of ADM has been positively correlated with cardiovascular disease and hypertension reviewed in Nikitenko et al. (2002). Here, we found $\mathrm{ADM}$ as a novel GC-target gene only in OM preadipocytes; its angiogenic and anti-lipolytic effects (Harmancey et al. 2005) might be an important factor explaining depot specificity of GC action in human adipose tissue.

\section{Genes involved in glucose metabolism/insulin signalling}

Many genes were similarly expressed and regulated by GCs in preadipocytes from both depots. Among them was the growth hormone receptor (GHR). GH has an anti-insulin activity (Roupas et al. 1991) and the upregulation of its receptor by GCs may be one mechanism underpinning GC-induced insulin resistance.

Insulin receptor substrate (IRS) plays a crucial role in adipogenesis; IRS2 $(-/-)$ embryonic mouse fibroblasts retain only $15 \%$ of their ability to differentiate to adipocytes (Miki et al. 2001). IRS2 knockout mice develop progressive deterioration in glucose homeostasis through impaired insulin signalling in the liver and skeletal muscle leading to type-2 diabetes (Withers et al. 1998). IRS2 expression was higher in OM than SC preadipocytes, but was induced to a similar extent by GCs in both depots.

PDK4, an enzyme involved in glucose metabolism and fatty acid synthesis is known to be expressed in skeletal muscle and adipose tissue (Rowles et al. 1996). Decreased PDK4 in muscle has been associated with increased insulin sensitivity (Rosa et al. 2003) and increased expression with insulin resistance, diabetes and hyperthyroidism reviewed by Sugden (2003). The relationship between PDK4 and glucocorticoids has been studied in HepG2 cells but not in human adipose tissue. Elevation of PDK4 expression in human preadipocytes might be an additional factor in GC-induced insulin resistance. 


\section{Anti-inflammatory}

In general, primary preadipocyte cultures isolated from human adipose tissue represent heterogeneous cell populations, some of which can be a part of the immune system (Kershaw \& Flier 2004). In this study, we observed GC effects on genes associated with immune responses, such as IL-6, TNFAIP6 and CD163. Activation of anti-inflammatory protein, TNFAIP6 (TNF $\alpha$-stimulated gene 6 ) gene by NF/IL-6 was previously demonstrated (Klampfer et al. 1995). The simultaneous GC-induced downregulation of the TNFAIP6 and IL-6 in human preadipocytes might reflect interaction between these two genes in adipose tissue inflammation. GPX3, plasma glutathione peroxidase 3 precursor, catalyses the reduction of hydrogen peroxide, organic hydroperoxide and lipid peroxides, thus protecting cells against oxidative damage. GPX3 was reported to be present in human adipose tissue (Maeda et al. 1997), and here we identified GPX3 expression as being one of the most highly expressed genes in preadipocyte compartment of human adipose tissue as well as a novel GC-target gene.

Recently, adipose tissue has been identified as a major production site of serum amyloid A (ASSA; Sjoholm et al. 2005), a known risk factor for coronary artery disease (Johnson et al. 2004). In this study, we have shown that ASSA is a GC-target gene in OM preadipocytes. Together, these findings contribute to the role of OM tissue as a potential link between an inflammatory response and coronary disease.

\section{Transcription factors}

Several transcription factors are known to be key regulators of the adipogenic processes, reviewed by MacDougald \& Mandrup (2002). In this study, we identified distinctively different as well as common sets of transcription factors involved in early glucocorticoidinduced adipogenesis in human SC and OM adipose tissues. Downregulation of Wnt-signalling pathway during adipogenesis has been shown in 3T3 cells (Bennett et al. 2002). Here, we demonstrate that the downregulation of Wnt-signalling pathway, as well as the induction of $\mathrm{C} / \mathrm{EBP} \alpha$ occurs only in $\mathrm{SC}$ preadipocytes. Different transcription factors, FOXO1A (upregulated in OM cells) and FOS (upregulated in SC cells), were the depot-specific early GC-targets genes. FOXO1 is induced in early stages of adipocyte differentiation (Nakae et al. 2003); our finding confirmed this but only in OM depots. Recently, involvement of two members of the zinc finger proteins family of the transcription factors, KLF2 and KLF15 has been reported in adipogenesis (Gray et al. 2002, Banerjee et al. 2003). Our study identified another member of this family, zinc finger protein 145 (ZFP145) as a novel, common,
GC-target in human preadipocytes. Moreover, the pattern of induction from undetectable levels suggests its important role in GCs-induced adipogenesis; however, the functional role of ZFP145 in adipose tissue needs to be further evaluated.

\section{Summary}

In summary, we have identified novel tissue-specific GC-target genes in SC and OM abdominal preadipocytes. The profile and intensity of fold changes in the expression of ten genes was confirmed by quantitative real-time PCR, indicating that the data obtained from our DNA array analysis are robust. The different sensitivity to GCs of SC and OM preadipocytes might explain heterogeneity as well as metabolic differences between these adipose depots in man.

\section{Acknowledgements}

We thank surgeons and theatre staff of Women's Hospitals at Birmingham for the adipose tissue collection and all women who volunteered to participate in the study for their contribution. We would also like to thank Dr Francesco Falciani for his help in analysing the microarrays. The authors declare that there is no conflict of interest that would prejudice the impartiality of this scientific work.

\section{References}

Ailhaud G, Dani C, Amri EZ, Djian P, Vannier C, Doglio A, Forest C, Gaillard D, Negrel R \& Grimaldi P 1989 Coupling growth arrest and adipocyte differentiation. Environmental Health Perspectives 80 17-23.

Atmani H, Chappard D \& Basle MF 2003 Proliferation and differentiation of osteoblasts and adipocytes in rat bone marrow stromal cell cultures: effects of dexamethasone and calcitriol. Journal of Cellular Biochemistry 89 364-372.

Badea TC, Niculescu FI, Soane L, Shin ML \& Rus H 1998 Molecular cloning and characterization of RGC-32, a novel gene induced by complement activation in oligodendrocytes. Journal of Biological Chemistry 273 26977-26981.

Banerjee SS, Feinberg MW, Watanabe M, Gray S, Haspel RL, Denkinger DJ, Kawahara R, Hauner H \& Jain MK 2003 The Kruppel-like factor KLF2 inhibits peroxisome proliferator-activated receptor-gamma expression and adipogenesis. Journal of Biological Chemistry 278 2581-2584.

Bennett CN, Ross SE, Longo KA, Bajnok L, Hemati N, Johnson KW, Harrison SD \& MacDougald OA 2002 Regulation of Wnt signaling during adipogenesis. Journal of Biological Chemistry 277 30998-31004.

Berger J, Tanen M, Elbrecht A, Hermanowski-Vosatka A, Moller DE, Wright SD \& Thieringer R 2001 Peroxisome proliferator-activated receptor-gamma ligands inhibit adipocyte 11 beta -hydroxysteroid dehydrogenase type 1 expression and activity. Journal of Biological Chemistry 276 12629-12635.

Blanchette S, Blouin K, Richard C, Dupont P, Luu-The V \& Tchernof A 2005 Expression and activity of 20\{alpha\}-hydroxysteroid 
dehydrogenase (AKR1C1) in abdominal subcutaneous and omental adipose tissue in women. Journal of Clinical Endocrinology and Metabolism 90 264-270.

Bronnegard M, Arner P, Hellstrom L, Akner G \& Gustafsson JA 1990 Glucocorticoid receptor messenger ribonucleic acid in different regions of human adipose tissue. Endocrinology 127 1689-1696.

Bujalska IJ, Kumar S \& Stewart PM 1997 Does central obesity reflect 'Cushing's disease of the omentum'? Lancet 349 1210-1213.

Bujalska IJ, Kumar S, Hewison M \& Stewart PM 1999 Differentiation of adipose stromal cells: the roles of glucocorticoids and 11betahydroxysteroid dehydrogenase. Endocrinology 140 3188-3196.

Burton GR, Guan Y, Nagarajan R \& McGehee RE Jr 2002 Microarray analysis of gene expression during early adipocyte differentiation. Gene 293 21-31.

Cervello M, Giannitrapani L, Labbozzetta M, Notarbartolo M, D'Alessandro N, Lampiasi N, Azzolina A \& Montalto G 2004 Expression of WISPs and of their novel alternative variants in human hepatocellular carcinoma cells. Annals of the New York Academy of Sciences 1028 432-439.

Cook JS, Lucas JJ, Sibley E, Bolanowski MA, Christy RJ, Kelly TJ \& Lane MD 1988 Expression of the differentiation-induced gene for fatty acid-binding protein is activated by glucocorticoid and cAMP. PNAS 85 2949-2953.

Derfoul A, Perkins GL, Hall DJ \& Tuan RS 2006 Glucocorticoids promote chondrogenic differentiation of adult human mesenchymal stem cells by enhancing expression of cartilage extracellular matrix genes. Stem Cells 24 1487-1495.

Despres JP 1998 The insulin resistance-dyslipidemic syndrome of visceral obesity: effect on patients' risk. Obesity Research 6 suppl 1 8S-17S.

Dong Y, Poellinger L, Okret S, Hoog JO, Bahr-Lindstrom H, Jornvall H \& Gustafsson JA 1988 Regulation of gene expression of class I alcohol dehydrogenase by glucocorticoids. PNAS 85 767-771.

Fernandes D, Guida E, Koutsoubos V, Harris T, Vadiveloo P, Wilson JW \& Stewart AG 1999 Glucocorticoids inhibit proliferation, cyclin D1 expression, and retinoblastoma protein phosphorylation, but not activity of the extracellular-regulated kinases in human cultured airway smooth muscle. American Journal of Respiratory Cell and Molecular Biology 21 77-88.

Fried SK, Russell CD, Grauso NL \& Brolin RE 1993 Lipoprotein lipase regulation by insulin and glucocorticoid in subcutaneous and omental adipose tissues of obese women and men. Journal of Clinical Investigation 92 2191-2198.

Fried SK, Bunkin DA \& Greenberg AS 1998 Omental and subcutaneous adipose tissues of obese subjects release interleukin6: depot difference and regulation by glucocorticoid. Journal of Clinical Endocrinology and Metabolism 83 847-850.

Friedberg M, Zoumakis E, Hiroi N, Bader T, Chrousos GP \& Hochberg Z 2003 Modulation of 11 beta-hydroxysteroid dehydrogenase type 1 in mature human subcutaneous adipocytes by hypothalamic messengers. Journal of Clinical Endocrinology and Metabolism 88 385-393.

Ginsberg HN, Zhang YL \& Hernandez-Ono A 2005 Regulation of plasma triglycerides in insulin resistance and diabetes. Archives of Medical Research 36 232-240.

Gray S, Feinberg MW, Hull S, Kuo CT, Watanabe M, Sen-Banerjee S, DePina A, Haspel R \& Jain MK 2002 The Kruppel-like factor KLF15 regulates the insulin-sensitive glucose transporter GLUT4. Journal of Biological Chemistry 277 34322-34328.

Gregoire F, Genart C, Hauser N \& Remacle C 1991 Glucocorticoids induce a drastic inhibition of proliferation and stimulate differentiation of adult rat fat cell precursors. Experimental Cell Research 196 270-278.

Handoko K, Yang K, Strutt B, Khalil W \& Killinger D 2000 Insulin attenuates the stimulatory effects of tumor necrosis factor alpha on 11 beta-hydroxysteroid dehydrogenase 1 in human adipose stromal cells. Journal of Steroid Biochemistry and Molecular Biology 72 $163-168$
Harmancey R, Senard JM, Pathak A, Desmoulin F, Claparols C, Rouet P \& Smih F 2005 The vasoactive peptide adrenomedullin is secreted by adipocytes and inhibits lipolysis through NO-mediated beta-adrenergic agonist oxidation. FASEB Journal 19 $1045-1047$.

Hauner H, Schmid P \& Pfeiffer EF 1987 Glucocorticoids and insulin promote the differentiation of human adipocyte precursor cells into fat cells. Journal of Clinical Endocrinology and Metabolism 64 832-835.

Hermanowski-Vosatka A, Gerhold D, Mundt SS, Loving VA, Lu M, Chen Y, Elbrecht A, Wu M, Doebber T, Kelly L et al. 2000 PPARalpha agonists reduce 11beta-hydroxysteroid dehydrogenase type 1 in the liver. Biochemical and Biophysical Research Communications 279 330-336.

Higuchi S, Matsushita S, Masaki T, Yokoyama A, Kimura M, Suzuki G \& Mochizuki H 2004 Influence of genetic variations of ethanolmetabolizing enzymes on phenotypes of alcohol-related disorders. Annals of the New York Academy of Sciences 1025 472-480.

Jamieson PM, Chapman KE, Edwards CR \& Seckl JR 199511 betahydroxysteroid dehydrogenase is an exclusive 11 beta-reductase in primary cultures of rat hepatocytes: effect of physicochemical and hormonal manipulations. Endocrinology 136 4754-4761.

Jensen MD 1997 Health consequences of fat distribution. Hormone Research 48 suppl 5 88-92.

Jessen BA \& Stevens GJ 2002 Expression profiling during adipocyte differentiation of 3T3-L1 fibroblasts. Gene 299 95-100.

Johnson BD, Kip KE, Marroquin OC, Ridker PM, Kelsey SF, Shaw LJ, Pepine CJ, Sharaf B, Bairey Merz CN, Sopko G et al. 2004 Serum amyloid $\mathrm{A}$ as a predictor of coronary artery disease and cardiovascular outcome in women: the National Heart, Lung, and Blood Institute-Sponsored Women's Ischemia Syndrome Evaluation (WISE). Circulation 109 726-732.

Kershaw EE \& Flier JS 2004 Adipose tissue as an endocrine organ. Journal of Clinical Endocrinology and Metabolism 89 2548-2556.

Klampfer L, Chen-Kiang S \& Vilcek J 1995 Activation of the TSG-6 gene by NF-IL6 requires two adjacent NF-IL6 binding sites. Journal of Biological Chemistry 270 3677-3682.

Kopelman PG 2000 Obesity as a medical problem. Nature $\mathbf{4 0 4}$ 635-643.

Kurokawa T, Sasada R, Iwane M \& Igarashi K 1987 Cloning and expression of cDNA encoding human basic fibroblast growth factor. FEBS Letters 213 189-194.

Lakshmi V \& Monder C 1988 Purification and characterization of the corticosteroid 11 beta-dehydrogenase component of the rat liver 11 beta-hydroxysteroid dehydrogenase complex. Endocrinology 123 2390-2398.

Laplante M, Sell H, MacNaul KL, Richard D, Berger JP \& Deshaies Y 2003 PPAR-gamma activation mediates adipose depot-specific effects on gene expression and lipoprotein lipase activity: mechanisms for modulation of postprandial lipemia and differential adipose accretion. Diabetes 52 291-299.

Lee MH, Reynisdottir I \& Massague J 1995 Cloning of p57KIP2, a cyclin-dependent kinase inhibitor with unique domain structure and tissue distribution. Genes and Development 9 639-649.

MacDougald OA \& Mandrup S 2002 Adipogenesis: forces that tip the scales. Trends in Endocrinology and Metabolism 13 5-11.

Maeda K, Okubo K, Shimomura I, Mizuno K, Matsuzawa Y \& Matsubara K 1997 Analysis of an expression profile of genes in the human adipose tissue. Gene 190 227-235.

Masuzaki H, Ogawa Y, Isse N, Satoh N, Okazaki T, Shigemoto M, Mori K, Tamura N, Hosoda K \& Yoshimasa Y 1995 Human obese gene expression. Adipocyte-specific expression and regional differences in the adipose tissue. Diabetes 44 855-858.

Mehra MR, Uber PA, Park MH, Scott RL, Ventura HO, Harris BC \& Frohlich ED 2004 Obesity and suppressed B-type natriuretic peptide levels in heart failure. Journal of the American College of Cardiology 43 1590-1595. 
Miki H, Yamauchi T, Suzuki R, Komeda K, Tsuchida A, Kubota N, Terauchi Y, Kamon J, Kaburagi Y, Matsui J et al. 2001 Essential role of insulin receptor substrate 1 (IRS-1) and IRS-2 in adipocyte differentiation. Molecular and Cellular Biology 21 2521-2532.

Miller SG, De VP, Guerre-Millo M, Wong K, Hermann T, Staels B, Briggs MR \& Auwerx J 1996 The adipocyte specific transcription factor C/EBPalpha modulates human ob gene expression. PNAS 93 $5507-5511$.

Moore JS, Monson JP, Kaltsas G, Putignano P, Wood PJ, Sheppard MC, Besser GM, Taylor NF \& Stewart PM 1999 Modulation of 11betahydroxysteroid dehydrogenase isozymes by growth hormone and insulin-like growth factor: in vivo and in vitro studies. Journal of Clinical Endocrinology and Metabolism 84 4172-4177.

Nakae J, Kitamura T, Kitamura Y, Biggs WH, III, Arden KC \& Accili D 2003 The forkhead transcription factor Foxol regulates adipocyte differentiation. Developmental Cell 4 119-129.

Nikitenko LL, Smith DM, Hague S, Wilson CR, Bicknell R \& Rees MC 2002 Adrenomedullin and the microvasculature. Trends in Pharmacological Sciences 23 101-103.

Rebuffe-Scrive M 1988 Steroid hormones and distribution of adipose tissue. Acta Medica Scandinavica. Supplementum 723 143-146.

Rosa G, Di Rocco P, Manco M, Greco AV, Castagneto M, Vidal H \& Mingrone G 2003 Reduced PDK4 expression associates with increased insulin sensitivity in postobese patients. Obesity Research 11 176-182.

Ross SR, Graves RA, Greenstein A, Platt KA, Shyu HL, Mellovitz B \& Spiegelman BM 1990 A fat-specific enhancer is the primary determinant of gene expression for adipocyte P2 in vivo. PNAS 87 9590-9594.

Roupas P, Chou SY, Towns RJ \& Kostyo JL 1991 Growth hormone inhibits activation of phosphatidylinositol phospholipase $\mathrm{C}$ in adipose plasma membranes: evidence for a growth hormoneinduced change in G protein function. PNAS 88 1691-1695.

Rowles J, Scherer SW, Xi T, Majer M, Nickle DC, Rommens JM, Popov KM, Harris RA, Riebow NL, Xia J et al. 1996 Cloning and characterization of PDK4 on 7q21.3 encoding a fourth pyruvate dehydrogenase kinase isoenzyme in human. Journal of Biological Chemistry $27122376-22382$.

Sengenes C, Berlan M, De GI, Lafontan M \& Galitzky J 2000 Natriuretic peptides: a new lipolytic pathway in human adipocytes. FASEB Journal 14 1345-1351.
Shiffman D, Ellis SG, Rowland CM, Malloy MJ, Luke MM, Iakoubova OA, Pullinger CR, Cassano J, Aouizerat BE, Fenwick RG et al. 2005 Identification of four gene variants associated with myocardial infarction. American Journal of Human Genetics 77 596-605.

Shindo T, Kurihara H, Kuno K, Yokoyama H, Wada T, Kurihara Y, Imai T, Wang Y, Ogata M, Nishimatsu H et al. 2000 ADAMTS-1: a metalloproteinase-disintegrin essential for normal growth, fertility, and organ morphology and function. Journal of Clinical Investigation 105 1345-1352.

Sjoholm K, Palming J, Olofsson LE, Gummesson A, Svensson PA, Lystig TC, Jennische E, Brandberg J, Torgerson JS, Carlsson B et al. 2005 A microarray search for genes predominantly expressed in human omental adipocytes: adipose tissue as a major production site of serum amyloid A. Journal of Clinical Endocrinology and Metabolism 90 2233-2239.

Stulnig TM, Oppermann U, Steffensen KR, Schuster GU \& Gustafsson JA 2002 Liver X receptors downregulate 11beta-hydroxysteroid dehydrogenase type 1 expression and activity. Diabetes 51 2426-2433.

Sugden MC 2003 PDK4: a factor in fatness? Obesity Research 11 167-169. Tomlinson JW, Moore J, Cooper MS, Bujalska I, Shahmanesh M, Burt C, Strain A, Hewison M \& Stewart PM 2001 Regulation of expression of 11beta-hydroxysteroid dehydrogenase type 1 in adipose tissue: tissue-specific induction by cytokines. Endocrinology 142 1982-1989.

Wang P, Mariman E, Keijer J, Bouwman F, Noben JP, Robben J \& Renes J 2004 Profiling of the secreted proteins during 3T3-L1 adipocyte differentiation leads to the identification of novel adipokines. Cellular and Molecular Life Sciences 61 2405-2417.

Williams LJ, Lyons V, MacLeod I, Rajan V, Darlington GJ, Poli V, Seckl JR \& Chapman KE 2000 C/EBP regulates hepatic transcription of 11 \{beta\}-hydroxysteroid dehydrogenase type 1; a novel mechanism for cross talk between the C/EBP and glucocorticoid signalling pathways. Journal of Biological Chemistry 275 30323-30329.

Withers DJ, Gutierrez JS, Towery H, Burks DJ, Ren JM, Previs S, Zhang Y, Bernal D, Pons S, Shulman GI et al. 1998 Disruption of IRS-2 causes type 2 diabetes in mice. Nature 391 900-904.

Received 5 June 2006

Accepted 29 June 2006 